\title{
Medial Lenticulostriate Artery
}

National Cancer Institute

\section{Source}

National Cancer Institute. Medial Lenticulostriate Artery. NCI Thesaurus. Code C33066.

The arteries branching off of the proximal middle cerebral artery that supply the medial region of the putamen and the globus pallidus. 